3. Geicke-Mathews, Evelyn C.. Elegance Paris, Printemps/ Ete ' 94 ( 1994).

4. Geicke-Mathews, Evelyn C., Elegance Paris, Automne/ Hiver '94/95 (1994).

5. Geicke-Mathews, Evelyn C., Elegance Paris, Printemps/ Ete '95 (1995).

6. Kawabata, S.. and Niwa, M.. Objective Evaluation of the Quality of Ladies' Garments, Int. J. Clothing Sci. Technol. 4 (5), 34-44 (1992).

7. Kawabata, S., and Niwa, M., Fabric Performance in Clothing and Clothing Manufacture, J. Textile Inst. 80, 19-50 (1989).

8. Kawabata, S., and Niwa, M., Improvement in the Objective Evaluation of Fabric Hand for Thin Dress Fabrics,
Part 1: Selection of the Fabric Deformation Range in the Measurement of Mechanical Properties. J. Textile Machin. Soc. Jpn. 37, T113-121 (1984).

9. Lindberg, J., Waesterberg, L., and Svenson, R., Wool Fabrics as Garment Construction Materials, J. Text. Inst. 51, T1475 (1960).

10. Niwa, M., Kawabata, S., and Ishizuka, K., in "Proc. 2nd Australia/Japan Symposium on Objective Measurement," R. Postle, S. Kawabata, and M. Niwa, Eds., The Textile Machinery Society of Japan. Osaka. Japan, 1983. pp. 67.

11. Tasaki, K.. private communication. 1995.

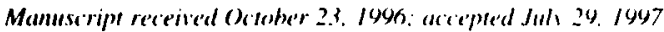

\title{
Influence of Hydrolytic and Chemical Treatment on the Mechanical Properties of Aramid and Copolyaramid Fibers
}

\author{
H. Springer, A. Abu Obaid, A. B. Prabawa, and G. Hinrichsen \\ Technical University of Berlin, Institute of Nonmetallic Materials, Polymer Physics Group, \\ D-10587 Berlin, Germany
}

\begin{abstract}
Commercial PPTA fibers (Kevlar $49^{\circledR}$ and Twaron $1055^{\mathfrak{A}}$ ) and copolyaramid fibers (Trevar ${ }^{\circledR}$ ) are subjected to various hydrolytic and chemical treatments. Tensile modulus, tensile strength, and elongation at break are measured, and mechanical property deterioration is compared. Copolyaramid fibers show improved hydrolytic stability and chemical resistance compared to PPTA fibers. The time dependence of degradation processes can be described by two decreasing exponential functions. WAXs measurements detect only slight differences in the crystalline structure and superstructure of the treated fibers. Thus, the main origin of mechanical degradation is the destruction of intercrystalline links such as tie molecules or tie crystallites.
\end{abstract}

Poly ( $p$-phenylene terephthalamide) (PPTA) fibers exhibit high values of tensile modulus and strength and high stability at elevated temperatures compared to conventional synthetic fibers $[4-6,10$, $11]$. Under moderate conditions, most organic solvents and aqueous salt solutions have little effect on the mechanical properties of PPTA fibers [11]. However, strong acids and bases as well as water at high temperature and pressure attack PPTA fibers $[3,8,11]$. In order to avoid this problem, copoly(terephthalamides) like Technora ${ }^{\circledR}$ and Tre-
$\operatorname{var}^{\circledR 1}[3,8,9]$ have been developed, using comonomers of higher flexibility and less linear structure. These copolymers can be directly spun from the polycondensation solution after neutralization and some other processes, and subsequent drawing yields highly oriented fibers. However, a less perfect crystalline superstructure and lower am-

\footnotetext{
' Technora ${ }^{8}$ and Trevar ${ }^{\mathbb{B}}$ are registered trademarks of Teijin Limited and Hoechst. respectively.
} 
ide concentration reduce water uptake drastically compared to PPTA fibers, thus increasing the resistance against hydrolytic and chemical degradation $|3,8|$.

In this paper, we compare the hydrolytic and chemical stability of Kevlar 49 and Twaron $1055^{\mathrm{kz}}$ fibers to that of Trevar fibers, applying the same experimental conditions to all fibers. With waxs experiments, we investigate the changes in crystalline structure and superstructure.

\section{Experimental}

For our comparison. we have used conventional PPTA fibers Kevlar 49 and Twaron 1055, and copolyaramid fibers Trevar 103, 106, and 107. Manufacturers" data for these fibers are listed in Table I. The additional comonomers of all Trevar fibers are 3,3'-dimethylbenzidine and 1,4-bis-( $4^{\prime}$-aminophenoxy)-benzene. The fibers differ in their finishing: Trevar 103 is prepared especially for reinforcing elastomers, and Trevar 106 and 107 have a slightly higher orientation than Trevar 103. The parameters of the hydrolytic and chemical treatments are shown in Table II.

Stress and strain were measured on a tensile testing machine (Instron 1121). The fiber ends were embedded in an epoxy resin: gauge length was set to $10 \mathrm{~cm}$ and the drawing rate to $20 \%$ /minute. For each measuring point, the average value of six samples was taken. Measuring fiber bundles without twist rather than monofilaments may be one reason for the discrepancy between the data for the untreated samples presented here and the manufacturers' data. This difference is of no relevance for this work, because our main intention is to investigate the relative amount of degradation, and the conditions were the same for all measurements.

: Kevlar ${ }^{k \mathrm{k}}$ and Twaron ${ }^{\wedge}$ are registered trademarks of Dupont and Akzo, respectively.
Wide angle $\mathrm{x}$-ray scattering measurements used $\mathrm{CuK}_{\alpha}$ radiation, and preliminary characterization was made with flat-film photographs. For quantitative analysis, carefully aligned fibers were placed in a Philips goniometer with curved crystal monochromator, which recorded equatorial as well as meridional scans of symmetrically transmitted intensities.

\section{Results and Discussion}

\section{TEMPERATURE DePENDENT TREatMents}

Temperature dependent treatments involve pure water and a water solution of 10 weight $\% \mathrm{NaCl}$ for 1 day at a temperature range of 100 to $180^{\circ} \mathrm{C}$. The measured values of tensile modulus. tensile strength, and elongation at break are plotted versus hydrolysis temperature in Figure 1. The mechanical properties of Trevar fibers are only slightly modified. and the tensile modulus even increases. On the other hand. there is a drastic decrease in all three mechanical quantities for Kevlar 49 and Twaron 1055, in agreement with results reported in the literature $|3.8|$. Adding $10 \% \mathrm{NaCl}$ to pure water lowers the degradation of the Kevlar fibers, whereas that of Twaron remains unchanged (Figures 2 and 3 ). This shielding effect of $\mathrm{NaCl}$ on the degradation of Kevlar was also mentioned by Bradley [2].

\section{Time Dependent Treatments}

\section{Tensile Modulus}

From the results of time dependent degradation experiments, the parameters of which are listed in Table II. we can conclude that the tensile modulus of Trevar fibers remains constant. In contrast. PPTA fibers under the chemical attack of $\mathrm{NaOH}$ solution and sulfuric acid show a significant decrease in the tensile modulus ( Figure 4). Figure 5 compares the effects of different degradation media on the tensile moduli of Kevlar 49 and

TABLE I. Fiher characterization according to the manufacturers' data.

\begin{tabular}{|c|c|c|c|c|c|}
\hline & Trevar $103^{\circledR}$ & Trevar $106^{\mathrm{B}}$ & Trevar $107^{8}$ & Kevlar $49^{\mathfrak{B}}$ & Twaron $1055^{(\mathbb{B}}$ \\
\hline $\begin{array}{l}\text { Tensile strength. } \\
\text { N/tex (GPa) }\end{array}$ & $\begin{array}{l}2.06 \\
(2.70)\end{array}$ & $\begin{array}{c}2.27 \\
(2.97)\end{array}$ & $\begin{array}{c}2.33 \\
(3.05)\end{array}$ & $\begin{array}{l}2.20 \\
(3.19)\end{array}$ & $\begin{array}{l}2.21 \\
(3.20)\end{array}$ \\
\hline Tensile modulus. & 58 & 61 & 61 & 73.6 & 84.8 \\
\hline N/tex (GPa) & (76) & $(80)$ & $(80)$ & (107) & $(123)$ \\
\hline Elongation at break. \% & 3.4 & 3.7 & 3.9 & 3.0 & 2.0 \\
\hline Number of filaments & 660 & 660 & 660 & 100 & 750 \\
\hline $\begin{array}{l}\text { Fiber diameter, } \mu \mathrm{m} \\
\text { Linear density. }\end{array}$ & $12.8-13$ & $12.8-13$ & $12.8-13$ & 12 & 12 \\
\hline $\begin{array}{c}\text { Linear density, } \\
\text { tex }=\cdot \mathrm{g} / \mathrm{km} \\
\text { Density. } \mathrm{g} / \mathrm{cm}^{3}\end{array}$ & $\begin{array}{c}110 \\
1.31-1.32\end{array}$ & $\begin{array}{c}110 \\
1.31-1.32\end{array}$ & $\begin{array}{c}110 \\
1.31-1.32\end{array}$ & $\begin{array}{r}166 \\
1.45\end{array}$ & $\begin{array}{l}121 \\
1.45\end{array}$ \\
\hline
\end{tabular}


TABLE II. Parameters of fiber treatment.

\begin{tabular}{lcc}
\hline \multicolumn{1}{c}{ Medium } & $\begin{array}{c}\text { Treatment } \\
\text { duration }\end{array}$ & $\begin{array}{c}\text { Treatment } \\
\text { temperature }\end{array}$ \\
\hline $\begin{array}{l}\text { Air at } 85 \% \text { relative } \\
\text { humidity }\end{array}$ & $\begin{array}{c}33 \mathrm{~d} \leq t \leq 93 \mathrm{~d} \\
1 \mathrm{~d} \leq t \leq 8 \mathrm{~d}\end{array}$ & $\begin{array}{c}85^{\circ} \mathrm{C} \\
120^{\circ} \mathrm{C}\end{array}$ \\
$\begin{array}{l}\text { Water } \\
\text { Water }\end{array}$ & $1 \mathrm{~d}$ & $100^{\circ} \mathrm{C} \leq T \leq 180^{\circ} \mathrm{C}$ \\
$\begin{array}{l}\mathrm{NaCl}, 10 \% \text { by } \\
\text { weight in water }\end{array}$ & $1 \mathrm{~d}$ & $100^{\circ} \mathrm{C} \leq T \leq 180^{\circ} \mathrm{C}$ \\
$\begin{array}{l}\mathrm{H}_{2} \mathrm{SO} .40 \% \text { by } \\
\text { weight in water }\end{array}$ & $0.5 \mathrm{~d} \leq t \leq 4 \mathrm{~d}$ & $(90 \pm 3)^{\circ} \mathrm{C}$ \\
$\begin{array}{l}\mathrm{NaOH} \text {. } 10 \% \text { by } \\
\text { weight in water }\end{array}$ & $0.5 \mathrm{~d} \leq t \leq 4 \mathrm{~d}$ & $(90 \pm 3)^{\circ} \mathrm{C}$ \\
\hline
\end{tabular}

“d = days.
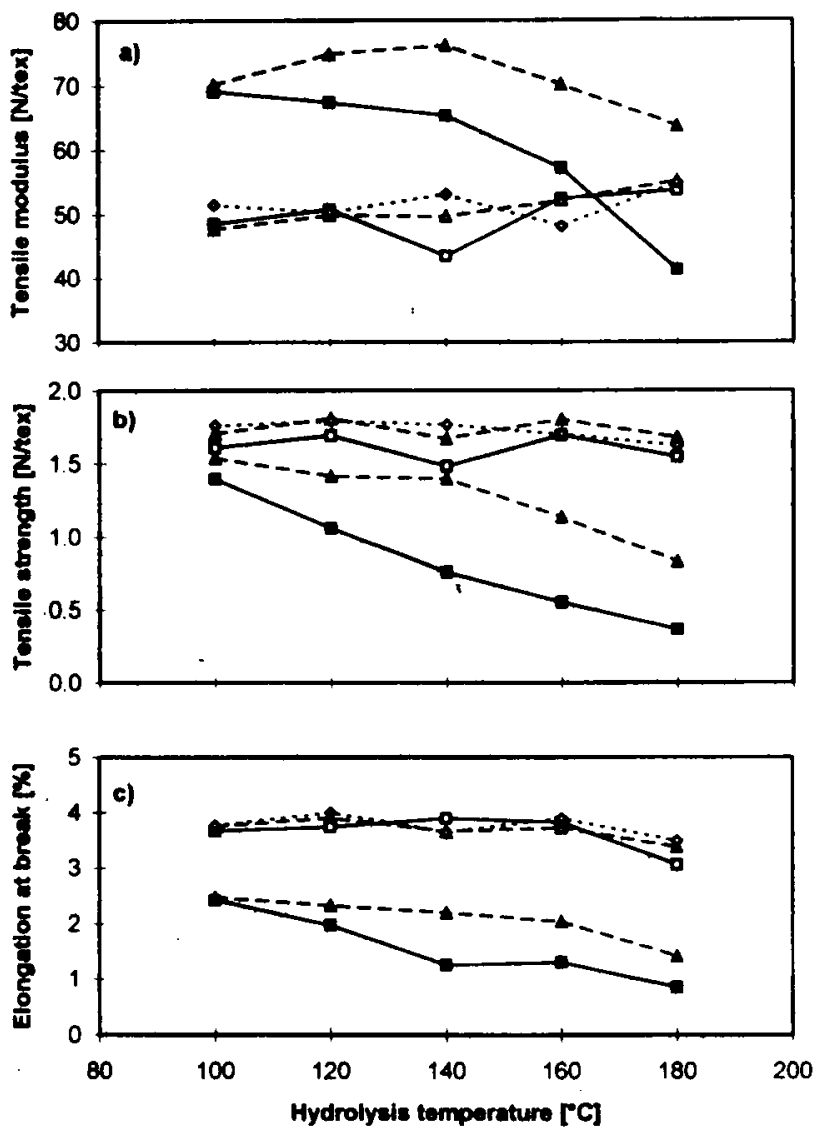

$\begin{array}{lll}\Rightarrow \text {-Trever1030 } & \text { - } \\ \Rightarrow \text { - Treviar490 } & \text { - Twaron10550 } & \cdots * \cdot \text { Trevar1070 }\end{array}$

FIGURE 1. Mechanical properties of aramid and copolyaramid fibers after I day of hydrolysis at different temperatures in pure water.

Twaron 1055; the maximum decrease in the moduli occurs after $\mathrm{NaOH}$ treatment.

\section{Tensile Strength}

Even more dramatically than the tensile modulus, tensile strength is affected by hydrolytic and chemical
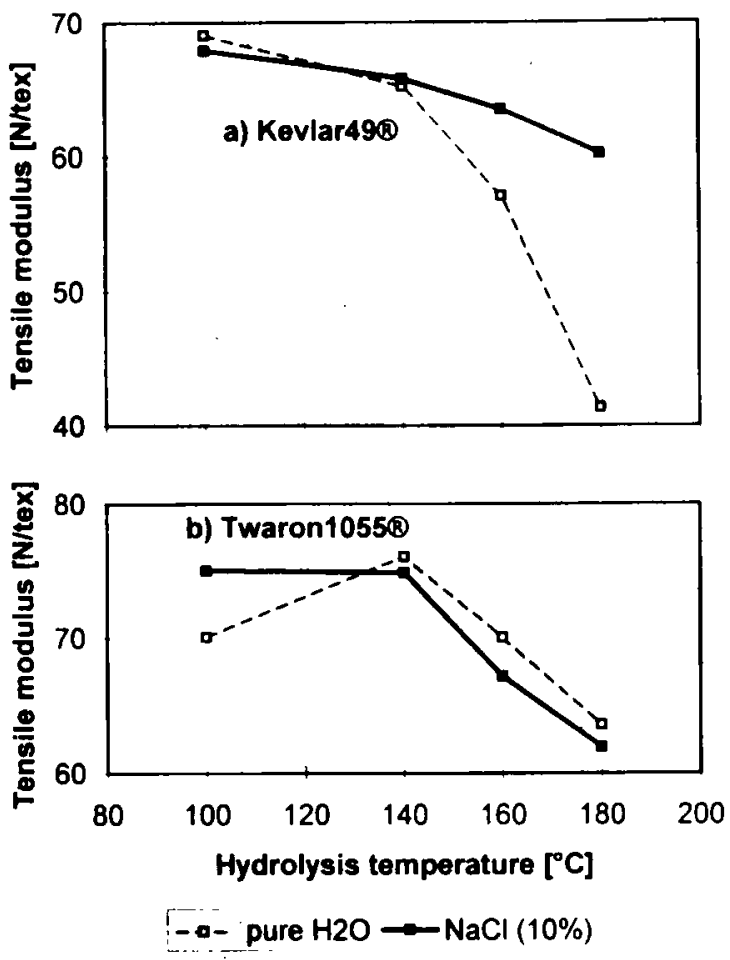

Figure 2. Tensile modulus of (a) Kevlar 49 and (b) Twaron 1055 treated with pure water or with $10 \% \mathrm{NaCl}$ solution for 1 day at different temperatures.

treatments (Figure 6). Although the tensile strength of Trevar fibers is reduced only to $90 \%$ with the chemical attack, the retained values of the PPTA fibers are as low as $30 \%$. Several authors have discussed the underlying process of degradation $[2,3,8,11]$. Auerbach [1] proposed a second order process and also considered the additional influence of an inhibitor at the beginning of degradation. He deduced the following equations in an integrated form:

$$
k_{a t} t=\frac{1}{\sigma}-\frac{1}{\sigma_{0}}
$$

and

$$
k t=\frac{1}{\alpha}\left(\frac{1}{\sigma}-\frac{1}{\sigma_{0}}\right)+\frac{1}{\alpha^{2}} \ln \frac{\sigma_{0}(\alpha-\sigma)}{\sigma\left(\alpha-\sigma_{0}\right)} .
$$

where $\sigma$ is tensile strength at time $t, k_{a}$ and $k$ are rate constants, $\alpha$ is a constant larger than the initial tensile strength $\sigma_{0}$, and $(\alpha-\sigma)$ is a term scaled to tensile strength values and inversely proportional to the concentration of the remaining inhibitors.

Fitting our data according to these equations does not yield a sufficient approximation, however. Instead, all tensile strength data from our work can be well fitted, assuming two simultaneously occurring decay processes described by the following equation: 

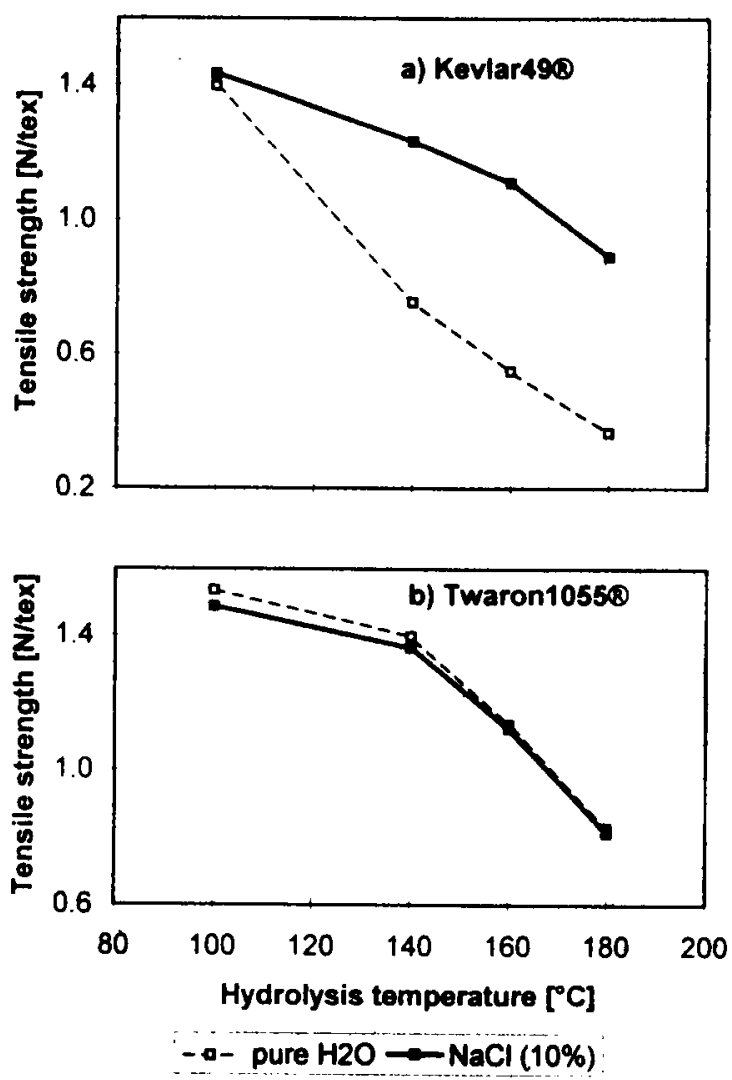

FIGicR: 3. Tensile strength of (a) Kevlar 49 and (b) Twaron 1055 treated with pure water or with $10 \% \mathrm{NaCl}$ solution for 1 day at different temperatures.

$$
\sigma=\sigma_{0}\left(\alpha_{1} \exp \frac{-t}{\tau_{1}}+\alpha_{2} \exp \frac{-t}{\tau_{2}}\right)
$$

where $\alpha_{1}$ and $\alpha_{2}$ represent the amount and $\tau_{1}$ and $\tau_{2}$ the decay time of the two processes, respectively. This is exemplified for PPTA fibers treated with $\mathrm{NaOH}$ solution and sulfuric acid in Figures 7 and 8. For comparison. Figure 7 also plots the (coinciding) fits according to Equations 1 and 2, showing an insufficient representation of the experimental data. From Figure 8 , we see that the literature data of PPTA degradation [8] can also be well fitted by two decay processes, starting at the same time but having different weights $\alpha_{1}$ and $\alpha_{2}$ and decay times $\tau_{1}$ and $\tau_{2}$. The parameters of the two degradation processes are listed in Table III. With the exception of the hydrolysis of Twaron, for all decay processes it is necessary to apply two distinct decay functions to get a good approximation of the measured values. The first process is characterized by weights ranging from 53 to $72 \%$ and decay times from 5 to 67 days. The second process runs more rapidly, exhibiting $\tau$ values between 3.4 and 12.2 hours and weights between 47 and $28 \%$. At the present time, it is not possible
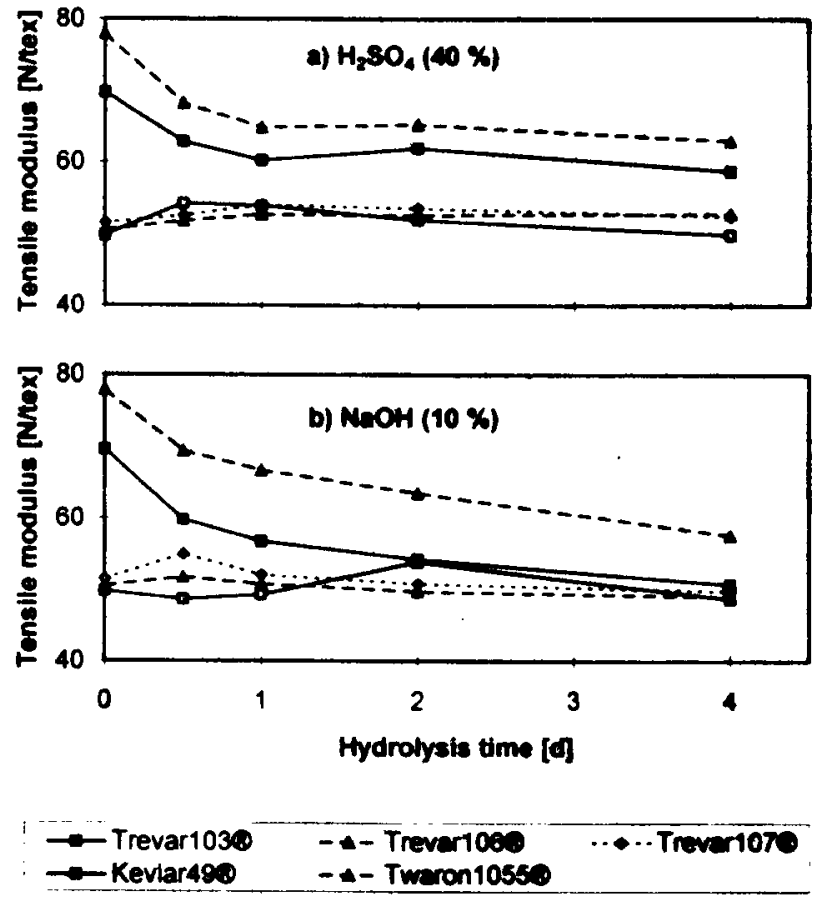

FIGURE 4. Tensile modulus of aramid and copolyaramid fibers treated at $90^{\circ} \mathrm{C}$ with ( a ) sulfuric acid and (b) soda liquor as a function of hydrolysis time.
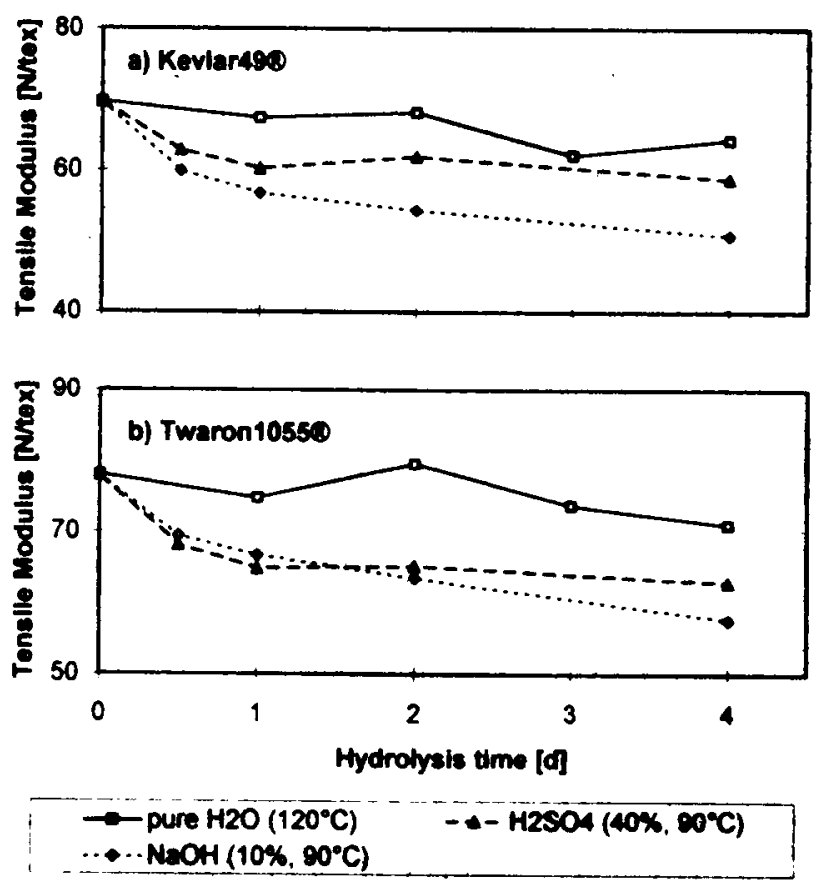

Figure 5. Tensile modulus of (a) Kevlar 49 and (b) Twaron 1055 tibers as a function of hydrolysis time. Parameter: hydrolysis medium and temperature.

to attribute the two functions to any real degradation mechanisms. The two processes may be assigned to two different fiber regions (e.g., core and shell or crys- 


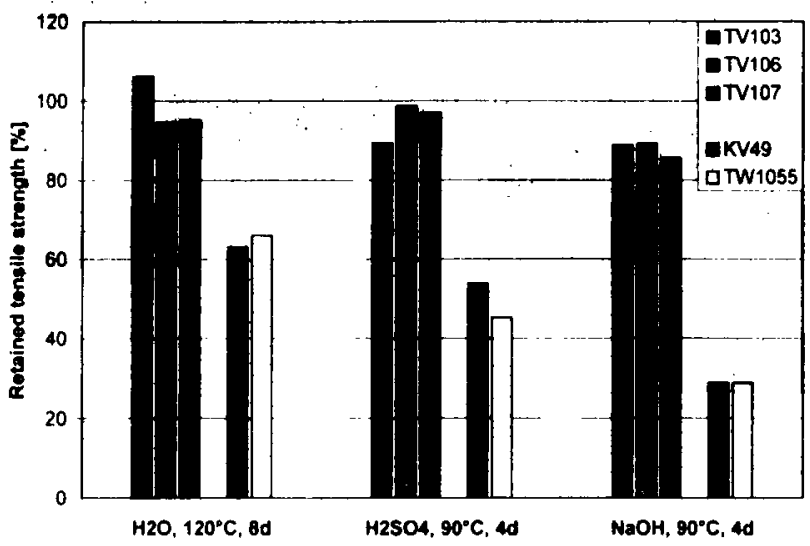

FiguRE 6. Retained tensile strength of aramid and copolyaramid fibers after longest treatment in different hydrolysis media.
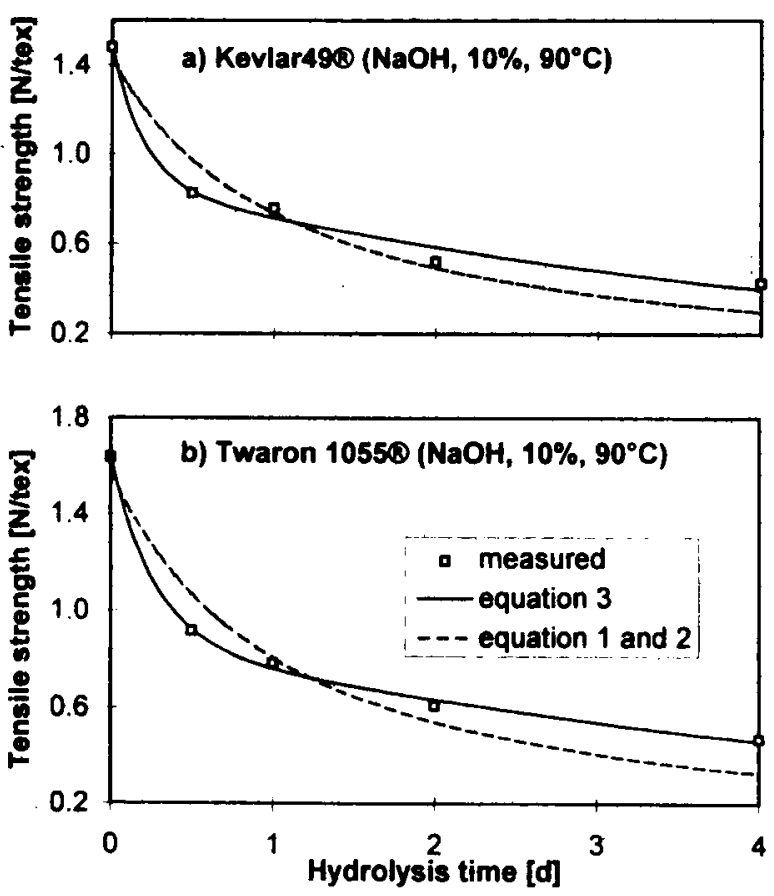

Figure 7. Tensile strength of (a) Kevlar 49 and (b) Twaron 1055 fibers treated with $10 \%$ soda liquor at $90^{\circ} \mathrm{C}$ as a function of hydrolysis time. The approximation according to Equations 1 and 2 yields the same curve.

talline and noncrystalline regions) or to structural elements being differently stressed (e.g., loose and taut tie molecules ).

\section{WAXS MEASUREMENTS}

The differences in the WAXS reflections of PPTA and copolyaramid fibers are illustrated in Figure 9 by comparing the flat-film $x$-ray photographs of untreated Kevlar 49 and Trevar 103 fibers. Kevlar shows sharp

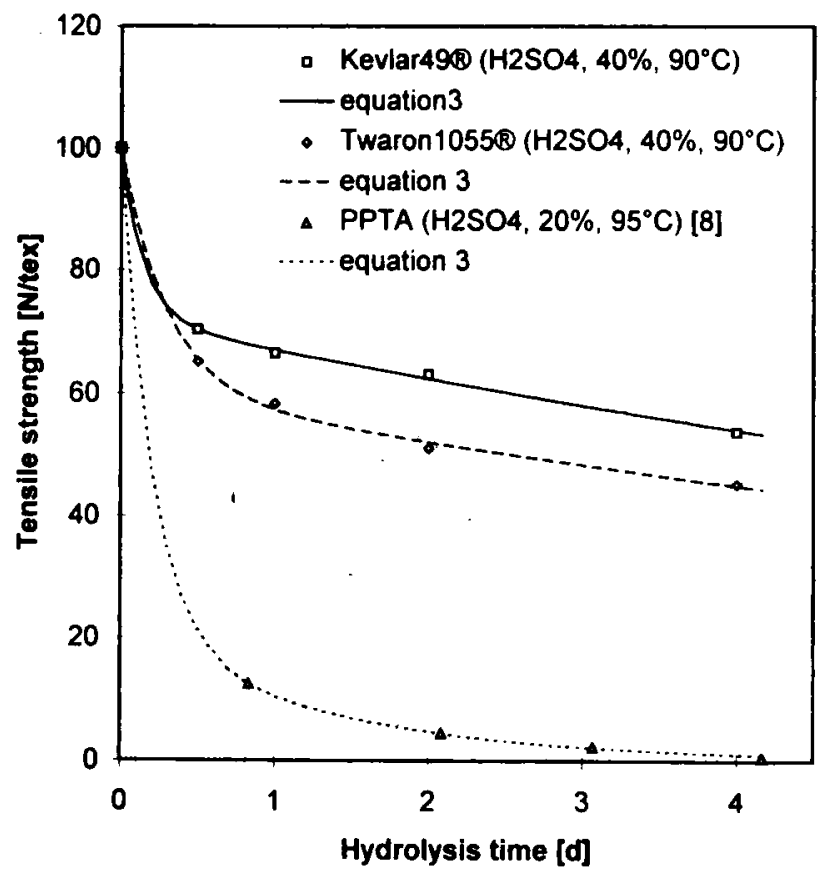

Figure 8. Tensile modulus of aramid tibers treated with sulfuric acid as a function of hydrolysis time.

equatorial (horizontally displayed) and meridional (vertically displayed) reflections, together with those of various layer lines, demonstrating the high degree of three-dimensional and orientational order. In contrast, Trevar 103 shows only meridional $(001)$ and equatorial ( h00) reflections, indicating a high order parallel but a low order perpendicular to the fiber axis. The flat-film photographs of all the fibers do not change significantly with degradation treatment.

Likewise, the WaXs goniometer measurements on Trevar 103 and Kevlar 49 show only small variations in structural parameters such as crystallinity, crystal size, and orientation factor, as can be seen from Tables IV and $\mathrm{V}$, respectively. For better understanding, the tensile modulus and strength of the fibers are also listed in these tables. Two crystallinity indices, $\alpha_{\mathrm{eq}}$ and $\alpha_{\mathrm{me}}$, are calculated from the equatorial and meridional $2 \theta$ scans, respectively.

For Trevar 103, only $\alpha_{\text {me }}$ and the first two meridional reflections are affected by the hydrolysis. The meridional crystallinity index $\alpha_{\text {me }}$ increases from $84 \%$ for the untreated fiber to about $95 \%$ for the hydrolyzed samples. The apparent thickness $D_{\text {mel }}$, corresponding to the various meridional crystalline reflections, behaves in a different manner: the thickness from the mel reflection increases, while that from the me 2 reflection decreases and that from the me 3 reflection remains almost constant. From this and also from the position of the reflections, it is obvious that the meridional reflections of 
TABI.F. III. Weights and decay times of functions used to fit the degradation curves.

\begin{tabular}{|c|c|c|c|c|c|}
\hline Fiber type & Parameter of fiber treatment & $\alpha_{1}, \%$ & $\tau_{1}$. days & $\alpha_{2}, \%$ & $T_{2}$. days \\
\hline Kevlar $49^{\mathbb{E}}$ & $\begin{array}{l}\text { water. } 120{ }^{\circ} \mathrm{C} \\
\mathrm{H}_{2} \mathrm{SO}_{4}, 40 \% \text { by weight in water } \\
\mathrm{NaOH} .10 \% \text { by weight in water }\end{array}$ & $\begin{array}{l}70 \\
72 \\
58\end{array}$ & $\begin{array}{r}67 \\
14 \\
5\end{array}$ & $\begin{array}{l}30 \\
28 \\
42\end{array}$ & $\begin{array}{l}0.51 \\
0.14 \\
0.20\end{array}$ \\
\hline Twaron $1055^{\mathbb{B}}$ & $\begin{array}{l}\text { water. } 1200^{\circ} \mathrm{C} \\
\mathrm{H}_{2} \mathrm{SO}_{4}, 40 \% \text { by weight in water } \\
\mathrm{NaOH} .10 \% \text { by weight in water }\end{array}$ & $\begin{array}{l}67 \\
60 \\
53\end{array}$ & $\begin{array}{r}22 \\
14 \\
6\end{array}$ & $\begin{array}{l}33 \\
40 \\
47\end{array}$ & $\begin{array}{r}22 \\
0.29 \\
0.27\end{array}$ \\
\hline
\end{tabular}
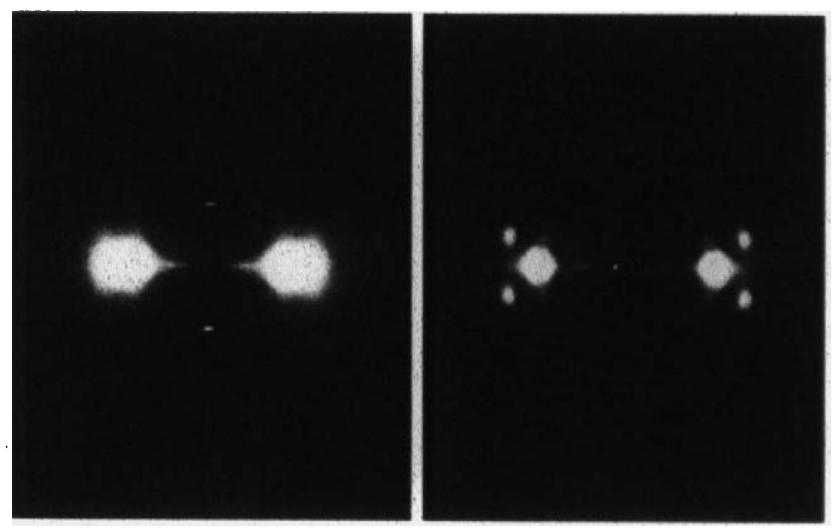

Figure 9. Flat-film x-ray photographs of untreated Trevar 103 (left) and Kevlar 49 ( right) fibers.

Trevar, unlike those of Kevlar or Twaron. cannot all originate from the same lattice plane. We will discuss this result in greater detail in a subsequent paper.

In Table V, the mechanical properties of Kevlar fibers decrease from left to right (depending on the degradation treatment ). The crystallinity indices, the paracrystalline lattice parameter along the $(-\mathrm{axis}(\mathrm{g})$, and the Hermans orientation factor of the (200) and (002) reflections are nearly constant. However, the apparent thickness corresponding to the equatorial reflections (110) and (200) grows slightly, whereas that corresponding to the $(002)$ reflection and. more clearly, the true crystallite thickness $\mathrm{L}(001)$, evaluated from the $(002),(004)$, and (006) reflections, decreases. From this result. we may conclude that some lateral growth in the lamellae takes place at a cost to their thickness. Hindeleh and others reported similar structural variations $[5,7]$ when Kevlar 49 was annealed at high temperatures or irradiated with $\mathrm{Co}^{60}-\gamma$ rays, respectively. This process may be initiated by cracking tie molecules, leading to a diminished correlation of supermolecular order parallel to the fiber direction. The broken tie molecules may then crystallize at the lateral surfaces of the lamellae.

\section{Conclusions}

Under various hydrolytic treatments in this work, the copoly-(terephthalamides) Trevar 103, 106. and 107 are clearly more stable than conventional PPTA fibers like Kevlar 49 and Twaron 1055, as established by their stress-strain behavior. The time dependent decrease of tensile strength in PPTA fibers can be fitted by the sum of two exponential decay functions. using decay times

TABLE: IV. Trevar $103^{(\mathbb{E}}$ : mechanical properties and structural parameters before and after hydrolysis.

\begin{tabular}{|c|c|c|c|c|}
\hline Hydrolysis parameter & Untreated & $\mathrm{H}_{2} \mathrm{SO}_{4} .90^{\circ} \mathrm{C}, 4$ days & $\mathrm{NaOH} .90^{\circ} \mathrm{C} .4$ days & $\mathrm{H}_{2} \mathrm{O} .180^{\circ} \mathrm{C} .1 \mathrm{day}$ \\
\hline \multicolumn{5}{|l|}{ Mechanical properties } \\
\hline Tensile modulus, N/tex & 49.8 & 49.9 & 48.7 & 53.7 \\
\hline Tensile strength, cN/tex & 1.55 & 1.38 & 138 & 154 \\
\hline \multicolumn{5}{|l|}{ Crystallinity indices } \\
\hline$\alpha_{\text {cy }}, \%$ & 77 & 78 & 79 & 76 \\
\hline$\alpha_{\mathrm{me}}, \%$ & 84 & 92 & 97 & 96 \\
\hline \multicolumn{5}{|l|}{ Apparent crystal thickness" } \\
\hline $\mathrm{D}_{\mathrm{e}_{41},}, \mathrm{~nm}(2 \theta=19.4)$ & 2.1 & 2.2 & 2.1 & 2.0 \\
\hline $\mathrm{D}_{\mathrm{e} 42}, \mathrm{~nm}(2 \theta=22.7)$ & 0.9 & 0.9 & 0.9 & 0.9 \\
\hline $\mathrm{D}_{\mathrm{mul}}, \mathrm{nm}(2 \theta=15.6)$ & 18.4 & 21.5 & 24.1 & 23.1 \\
\hline $\mathrm{D}_{\mathrm{me2} 2}, \mathrm{~nm}(2 \theta=27.6)$ & 3.8 & 2.1 & 2.2 & 2.5 \\
\hline $\mathrm{D}_{\operatorname{me} 3}, \mathrm{~nm}(2 \theta=42.6)$ & 4.2 & 3.9 & 4.3 & 4.0 \\
\hline \multicolumn{5}{|l|}{ Hermans' orientation factor } \\
\hline $\mathfrak{f}_{\mathrm{h}, \mathrm{eu}}$ & -0.45 & -0.45 & -0.45 & -0.45 \\
\hline $\mathbf{f}_{\text {h,mel }}$ & 0.97 & 0.97 & 0.96 & 0.97 \\
\hline$f_{\text {h.me: }}$ & 0.91 & 0.90 & 0.90 & 0.89 \\
\hline
\end{tabular}

\footnotetext{
${ }^{\lrcorner}$Evaluated from corresponding equatorial or meridional reflections.
} 
TABLE V. Kevlar $49^{\circledR}$ : mechanical properties and structural parameters before and after hydrolysis.

\begin{tabular}{|c|c|c|c|c|}
\hline Hydrolysis parameter & Untreated & $\mathrm{H}_{2} \mathrm{SO}_{4}, 90^{\circ} \mathrm{C}, 4$ days & $\mathrm{NaOH}, 90^{\circ} \mathrm{C}, 4$ days & $\mathrm{H}_{2} \mathrm{O}, 180^{\circ} \mathrm{C}, 1$ day \\
\hline \multicolumn{5}{|l|}{ Mechanical properties } \\
\hline Tensile modulus, N/tex & 69.6 & 58.7 & 50.8 & 41.3 \\
\hline Tensile strength, $\mathrm{cN} / \mathrm{tex}$ & 148 & 80 & 43 & 37 \\
\hline \multicolumn{5}{|l|}{ Crystallinity indices } \\
\hline$\alpha_{\mathrm{eq}}, \%$ & 90 & 89 & 92 & 90 \\
\hline$\alpha_{\text {mec }}, \%$ & 90 & 93 & 90 & 93 \\
\hline \multicolumn{5}{|l|}{ Apparent crystal thickness" } \\
\hline $\mathrm{D}_{111}, \mathrm{~nm}$ & 4.8 & 4.7 & 5.2 & 5.4 \\
\hline $\mathrm{D}_{200}, \mathrm{~nm}$ & 3.8 & 3.7 & 4.0 & 4.4 \\
\hline $\mathrm{D}_{002}, \mathrm{~nm}$ & 39.9 & 37.1 & 38.6 & 37.9 \\
\hline \multicolumn{5}{|l|}{ True crystal thickness ${ }^{b}$} \\
\hline $\mathrm{L}_{101}, \mathrm{~nm}$ & 90 & 83 & 85 & 78 \\
\hline Paracrystalline lattice parameter & & & & \\
\hline g. $\%$ & 2.8 & 2.9 & 2.8 & 2.8 \\
\hline \multicolumn{5}{|l|}{ Hermans' orientation factor } \\
\hline$f_{h .200}$ & -0.47 & -0.46 & -0.47 & -0.47 \\
\hline $\mathrm{f}_{\mathrm{h} .002}$ & 0.96 & 0.94 & 0.95 & 0.95 \\
\hline
\end{tabular}

of 5-70 days and 3-12 hours, respectively. The crystalline overall structure is only slightly modified by hydrolysis, however, and there are some hints that with PPTA, the degradation process may be initiated by the destruction of taut tie molecules or crystal bridges between the lamellae.

\section{Literature Cited}

I. Auerbach, I., Kinetics for the Tensile Strength Degradation of Nylon and Kevlar Yarns, J. Appl. Polym. Sci. 37, 2213-2227 (1989).

2. Bradley, W. L., The Effect of the Moisture Absorption on the Interfacial Strength of Polymeric Matrix Composites, J. Mater. Sci. 30, 5537-5542 (1992).

3. Heinrich, K., and Jung, H., New Concepts in para-Aramid Fibers, Textile Res. J. 62 (12), 771-775 (1992).

4. Heintze, A., Hochfeste Aramidfasern - ihre Eigenschaften und Anwendungsmöglichkeiten, Melliand Textilber. 67, 529-532 (1986).

5. Hindeleh, A. M., and Abdo, Sh. M., Relationship between Crystalline Structure and Mechanical Properties in
Kevlar ${ }^{\circledR} 49$ Fibres, Polym. Commun. 30, 184-186 (1989).

6. Hindeleh, A. M., Halim, N. A., and Ziq, K. A., SolidState Morphology and Mechanical Properties of Kevlar 29 Fiber, J. Macromol. Sci. Phys. B23 (3), 289-309 (1984).

7. Hindeleh, A. M., Hosemann, R., Hinrichsen, G., and Springer, H., Lateral Growth of Microparacrystals in Kevlar 49 Fibers Irradiated by $\mathrm{Co}^{60}, \mathrm{~J}$. Polym. Sci. Part B Polym. Phys. 28, 267-279 (1990).

8. Ozawa, S., A New Approach to High Modulus, High Tenacity Fibers, Polym. J. 19 (1), 119-125 (1987).

9. Wang, C. H., and Chen, L.-W., Preparation and Properties of Aramids Based on Naphthalenedicarboxylic Acid and their Molecular Composites with Amorphous Nylon, Angew. Makromol. Chem. 237, 173-189 (1996).

10. Wilfong, R. E., and Zimmerman, J., Strength and Durability of Kevlar Aramid Fiber, J. Appl. Polym. Sci. Appl. Polym. Symp. 31, 1-21 (1977).

11. Yang, H. H., "Kevlar Aramid Fiber," John Wiley \& Sons, Chichester, U.K., 1993.

Manuscript received March 5, 1997; accepted September 30, 1997. 